\title{
Acute effect of the ischemic compression technique on the EMG activity of the muscle upper trapezius in subjects with myofascial trigger points
}

\author{
Thomas Ângelo Miguel Gelmini (1), Patrícia Cilene Freitas Sant'Anna ${ }^{(1)}$, William Dhein ${ }^{(2)}$, Marcelo La Torre ${ }^{(1)}$
}

\begin{abstract}
Background: Myofascial trigger points (MTP) are palpable painful nodules in a shortened area of a given muscle. The ischemic compression technique (IC), which consists of pressing the painful nodule until the elimination of tension or pain, has been shown to be an alternative for the treatment of MTP. The objective of this study was to analyze the influence of the IC technique on the level of pain to the palpation and electrical activity of the right upper trapezius (RUT) muscle during the elevation of the shoulder girdle and abduction of the shoulder in subjects with MTP. Methods: The sample consisted of ten subjects with mean age of $25.9 \pm 2.68$ years, who performed scapula elevation and right shoulder abduction up to 180 o before and after the IC technique on the RUT muscle. The pain level was measured before and after the application of the IC technique and the myoelectric activity during the movements. Data analysis and processing were performed using the BIOMEC-SAS software and were presented in percentage values of the maximum voluntary isometric contraction (\%MVIC). Statistical analysis were performed using the Wilcoxon test $(\alpha<0.05)$. Results: There was a significant increase in the mean $\%$ of activation $(p=0.007)$ and in the peak $\% \mathrm{MVIC}(\mathrm{p}=0.005)$ of the myoelectric activity of the RUT muscle during the elevation movement of the right scapula. There was also a significant difference in the reduction of the level of pain referred to palpation $(p=0.004)$. There were no differences during abduction movements. The calculation of the effect size showed that the IC technique had great influence on the results found in this study. Conclusion: The IC technique is an important resource for pain modulation and alteration of the myoelectric activity in MTP patients and can be used by physiotherapists when indicated.
\end{abstract}

Keywords: Musculoskeletal Manipulations. Shoulder Joint. Electromyography

\section{INTRODUCTION}

Myofascial trigger points (MTPs) are a very common source of localized musculoskeletal pain. It is estimated that around $85 \%$ of the world's population has MTPs throughout the life ${ }^{(1)}$. As characteristics, stands out the presence of a palpable painful nodule in a shortened area of the muscle, with or without signs such as referred pain in the muscle or pain derived from palpation. MTPs can be classified as active, when they produce pain, or latent, when they are asymptomatic until they are palpated ${ }^{(2)}$.

The pathophysiology of the formation of MTPs has not yet been fully elucidated, but strong indications point to its emergence from a neuromuscular dysfunction resulting from muscular overload. Harmful conditions such as acute, sustained or repetitive functional overload, macro or microtraumas, shortened position (immobilization) of the muscle and inflammatory or infectious processes would lead the tissue to energy crisis causing damage to the level of motor plaques and finally sensitizing the nociceptors places causing pain ${ }^{(3,4)}$.

Manual therapy through the ischemic compression (IC) technique has been shown to be a very effective alternative for the treatment of MTPs. The technique consists of pressing the painful nodule until the cessation of tension or pain caused by pressure ${ }^{(5,6)}$.

A way to understand the neuromuscular behavior in the presence of MTPs is by electromyography (EMG) ${ }^{(7,8)}$. In addition, the EMG can also evaluate the effects of the application of the techniques used in physiotherapeutic treatments ${ }^{(9,10)}$.

Thus, the objective of this study was to analyze the effect of the IC technique on the level of pain to palpation and electrical activity of the RUT muscle during elevation of the shoulder girdle and abduction of the shoulder in subjects with MTPs.

Corresponding Author:

Thomas Ângelo Miguel Gelmini, Rua Irmão José Sion 944, Bairro Chácaras, Garibaldi, RS, Brasil. CEP 95720-000; E-mail: gelmini@gmail.com; Telephone: +55 54999912152

1 Universidade do Vale do Rio dos Sinos (UNISINOS), São Leopoldo (RS), Brasil

Full list of author information is available at the end of the article

Financial support: The authors declare that there was no financial support.

Submission date 28 February 2018; Acceptance date 03 July 2018; Publication date 11 October 2018 


\section{METHODS}

This is a semi-experimental research, previously approved by the Research Ethics Committee of the Universidade do Vale do Rio dos Sinos (UNISINOS), with number 1.876.088; all the participants signed the Free and Informed Consent Form.

The sample consisted of ten subjects $(n=10)$, six men and four women with mean age of $25.9 \pm 2.6$ years, with MTPs in the RUT muscle. To participate in the research, the subject should have a palpable painful nodule in combination with one or both of the following signs: (1) Reflex to the palpation due pain; (2) pain in the RUT area; as both are diagnostic signs of the presence of MTPs ${ }^{(3)}$. Exclusion criteria were: less than 150 o range of motion (ROM) for abduction of the right shoulder; inability to raise the right scapula; skin lesions in the RUT muscle region.

The data collection was performed in one step, with a single evaluator, in the Clinical School of Physiotherapy of the Universidade do Vale do Rio dos Sinos (UNISINOS). For the procedure were used: 16-channel electromyograph (EMG SYSTEM DO BRASIL LTDA São José dos Campos - SP, Brazil) equipped with a 32-bit A / D converter connected to a Dell notebook; surface electrodes $(\mathrm{Ag} / \mathrm{AgCl})$ in the bipolar configuration; digital metronome; disposable shaving appliances; cotton and alcohol.

The subjects were placed in a chair where they underwent an evaluation. It was performed in sequence: palpation in the RUT muscle region; assessment of active ROM of the right shoulder for abduction and assessment of the ability to raise the right scapula. During palpation, the subjects were asked about the pain sensation and instigated to classify it according to the Numerical Rating Scale (NRS) and Verbal Rating Scale (VRS).

Before the placement of the electrodes the skin was prepared, and after familiarization of the movements ${ }^{(11)}$ the electrodes were positioned according to SENIAM recommendations, between the motor point of the RUT muscle and the acromion, $20 \mathrm{~mm}$ apart, and following the orientation of the muscle fibers of the muscle. The reference electrode was placed on the spinous process of C7 (Figure 1) ${ }^{(12)}$. The electrodes were kept in the same place during the entire data collection.

After the training of the movements, there was an interval of 5 minutes, and then the MVIC collection with the objective of normalizing the myoelectric signals captured during the movements ${ }^{(11)}$. Between each collection there was a rest interval of 3 minutes. Two MVICs were performed to elevate the right scapula, maintaining the contraction for 5 seconds. After that, the sequence of movements of the right scapula elevation was requested six times according to previous training. Subsequently, the abduction of the right shoulder was performed up to the maximum ROM for six times. During the MVICs and proposed exercises, surface EMG signals were acquired in the bipolar configuration by a 16-channel electromyograph EMG System.
After the acquisition of the myoelectric signals, in the same sitting position, the subjects received the IC technique, through a pressure that persisted until the end of the pain sensation. After the application of the IC technique, the procedures for capturing the myoelectric signals were performed again, similar to the previous one. At the end of the collection, palpation was performed again on the RUT muscle to classify the pain level.

The analysis of electromyographic data was performed through the BIOMEC-SAS software (Universidade Federal do Rio Grande do Sul - UFRGS - Porto Alegre - RS - Brazil) ${ }^{(13)}$. Initially the signals collected during the MVICs and the scapula elevation and right shoulder abduction tasks were submitted to a digital filtering procedure using a fourth order Butterworth filter with a bandpass between 20 and $450 \mathrm{~Hz}$. The electromyographic signals were processed in the time domain from root mean square (RMS) envelope calculation with 1-second Hamming. The RMS signs calculated during the the scapula elevation and right shoulder abduction tasks were normalized from the highest peak value of the RMS envelope obtained in the two MVICs performed. After normalization, the six curves corresponding to the repetitions performed during the movements were cut out, discarding the first and last, leaving four curves equivalent to four repetitions. From the four curves, the means and standard deviations of each subject were calculated, resulting in 10 values of mean $\%$ of activation and 10 values of peak\% MVIC in each movement before and after the application of the IC technique.

The data were processed and analyzed by the Microsoft Office Excel (2010) and SPSS version 21.0 programs

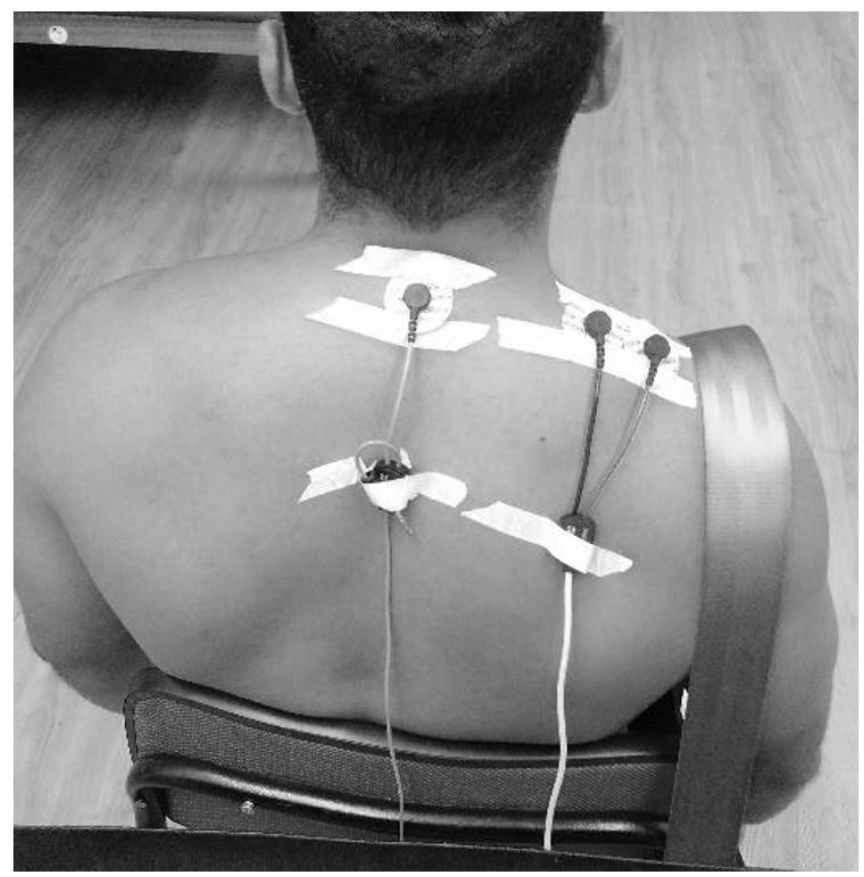

Figure 1 - Electrode Positioning. 
Table 1: Percentage of Mean, standard deviations of electrical activation normalized by MVIC during the movements of scapula elevation and abduction of the shoulder and effect size $(n=10)$

\begin{tabular}{lcccc}
\multicolumn{1}{c}{ RMS value } & Before IC $($ mean \pm SD) & After IC (mean \pm SD) & Value of $p$ & Effect size \\
\hline Scapula Elevation (\%) & $20.96 \pm 8.20$ & $25.64 \pm 9.42$ & $0.007^{*}$ & 0.603 \\
Shoulder Abduction (\%) & $24.93 \pm 9.43$ & $24.13 \pm 8.21$ & 0.799 & 0.08 \\
\hline
\end{tabular}

Note: * significant difference $(\alpha<0.05)$

Table 2: Mean, standard deviations of peak values of muscle activation normalized by MVIC during right shoulder scapula and shoulder abduction movements and effect size $(n=10)$

\begin{tabular}{lccc}
\hline \multicolumn{1}{c}{ Peak value } & Before IC (mean \pm SD) & After IC (mean \pm SD) & Value of p \\
\hline Scapula Elevation (\%) & $45.33 \pm 19.18$ & $58.80 \pm 23.94$ & $0.005^{*}$ \\
Shoulder Abduction (\%) & $44.65 \pm 19.78$ & $45.63 \pm 22.28$ & 0.626 \\
\hline
\end{tabular}

Note: * significant difference $(\alpha<0.05)$

Table 3 - Pain before X Pain after (NRS/VRS) and effect size $(n=10)$

\begin{tabular}{cc}
\multicolumn{2}{c}{ Pain (NRS/VRS) } \\
\hline Before IC & $6.5 \pm 1.43$ \\
After IC & $2.8 \pm 1.31$ \\
Value of $\alpha$ & $0.004^{*}$ \\
Effect size & -0.637 \\
\hline
\end{tabular}

Note: *significant difference $(\alpha<0.05)$

(SPSS Inc., Chicago, IL, USA), being described in means and standard deviations of the analyzed variables, comparing the before and after the interventions and considering a significance value of $5 \%(\alpha \leq 0.05)$. Due to the sample size $(n=10)$, it was used the non-parametric Wilcoxon test ${ }^{(14)}$.

To describe the effect observed in this study from the application of the IC technique, it was chosen to perform the effect size calculation ${ }^{(15)}$. Thus, the formula " $r=Z / V(N)$ " was used, in which " $r$ " represents the effect size, " $Z$ " the sample distribution and " $\mathrm{N}$ " the total number of observations. For comparison of results, the found effect size values indicate small effects (<0.1), medium effects (between 0.1 and 0.3 ) and large effects $(>0.5)^{(16)}$.

\section{RESULTS}

Table 1 shows the means, standard deviations of muscle activation normalized by MVIC during scapula elevation tasks, abduction of the right shoulder before and after the execution of the IC maneuver, and size of the effect.

When the myoelectric activity was evaluated during the scapular elevation movement after the application of the IC technique, it was verified that there was a statistically significant increase between the values registered after the application of the IC technique (Table 1). However, when the results were observed during shoulder abduction, there were no differences in the magnitudes of the EMG signal.
Table 2 presents the means and standard deviations of the peak values of muscle activation normalized by the MVIC during the movements of scapula elevation and shoulder abduction before and after the execution of the IC technique and the effect size.

There was a significant increase in the peak values of the MVIC\% of the RUT muscle during the right scapula elevation movement after the application of the IC technique (Table 2). However, for the peak values during shoulder abduction no differences were observed after the IC technique.

Table 3 shows the means and standard deviations for pain to palpation in the NRS/VRS, noting the decrease in pain sensation of the subjects who received the IC technique.

It can be observed that in the three situations mentioned above, in which there was a significant difference in the results, the found effect size values were $>0.5$, indicating that the IC technique had great influence on the EMG variable of this study ${ }^{(16)}$.

\section{DISCUSSION}

The application of the IC technique resulted in a decrease in pain levels and an increase in the myoelectric activity of the RUT during the scapula elevation movements. There were no significant changes during the right shoulder abduction movements.

Considering the physiology of pain reduction after the application of IC technique, some studies have based the application of the technique to the induction of transient local ischemia followed by increased perfusion after decompression, which would increase aerobic metabolism and ATP levels, culminating in decreased of pain ${ }^{(6,17-19)}$. Otherwise, citations are found on the application of the IC technique by the action on the sensory system through the inverse myotatic reflex, i.e., the pressed muscle would have its fibers shortened by digital pressure until reaching the threshold of activation of the Golgi tendon organs, generating inhibitory potentials on the alpha motoneuron, culminating in relaxation of the 
muscle and consequent decrease of pain ${ }^{(5)}$. Despite the lack of agreement regarding physiology, studies are unanimous in concluding that the IC technique is effective in decreasing pain levels soon after its application $(5,17,18,20,21)$.

In this study, the collection of myoelectric activity was chosen in two distinct movements with different results. This may have been due to the fact that, during elevation of the scapula, the upper trapezius muscle is the primary motor and, during abduction of the shoulder until approximately 900 it is in a situation of relative rest ${ }^{(22)}$. According to previous studies, in the resting condition, the myoelectric activity would be reduced by the application of IC technique and consequent treatment of MTPS $(7,20,23)$, while during contraction, it would be increased ${ }^{(6)}$.

Bigongiari et al. (7) indicate that the IC technique would normalize a neuromuscular dysfunction present in muscles with MTPs, caused by the excessive release of acetylcholine (Ach) from an autonomic modulation stimulated by the release of chemical substances that causes increases in the myoelectric activity in the resting situation. Whereas Teixeira et al. ${ }^{(19)}$, show that the neuromuscular dysfunction, which would provoke the increase in the myoelectric activity, would come from the abnormal release of Ach in the motor plate by the terminal nerve, provoking a contracted "knot", allowing contractile effects. In view of these physiological events, the action of the IC technique would reverse this situation, because by promoting an increase in the local blood circulation, the muscle would reach an adequate metabolic state, reducing the excess of Ach, culminating in the decrease of the myoelectric activity during rest ${ }^{(24)}$.

As in the present study, other studies also show the benefit of the IC technique. Bigongiari et al. ${ }^{(7)}$, with the objective of detecting changes in the electrical activity of muscles with MTPs in resting, found lower values of muscle electric activity in subjects who did not have MTPs. MontañezAguilera et al. ${ }^{(20)}$, evaluated the acute effect of the IC technique in a female patient with a complaint of cervicalgia and who presented MTPs in the left UT muscle. They found a decrease in the basal electrical activity, the pain sensation as well as an increase in ROM.

Teixeira et al. ${ }^{(19)}$ analyzed the immediate effect of the IC technique on the inhibition of MTPs in the UT muscle in 24 subjects (both gender; 18-30 years old) with active or latent MTPs. Evaluations were made regarding subjective pain sensation and myoelectric activity before and immediately after the application of the IC technique. There was a decrease in pain sensation, without significant changes in the electromyographic signal. These outcomes may be by the fact that the electrodes were removed between the electromyographic ratings, which may altered its positioning and consequently the captured signal ${ }^{(25)}$. In the present study, precautions were taken so that the electrodes were not removed between procedures, remaining all the time in the same position.

For future studies, new methodologies are suggested considering a control group to verify the differences in the magnitudes of the EMG signal between healthy and MTPS subjects. It should also be noted that kinematic data were not acquired, especially the scapular kinematics. This fact could help in the understanding of the contributions of IC techniques on the muscle and its consequent effects on kinematics.

\section{CONCLUSION}

There was a significant increase in the mean percentage value normalized by the MVIC and in the peak of the \%MVIC of myoelectric activity of the RUT during the right scapula elevation movements and decrease of the pain sensation to palpation in the RUT region. However, the application of the technique did not alter the myoelectric activity during the shoulder abduction movement. Thus, the study provides indications of the contribution of the IC technique to subjects with MTPs, noting its importance as a resource used by physiotherapy.

\section{AUTHORS' CONTRIBUTION:}

TAMG: development of the study, data collection, data analysis, discussion and article writing; PCFS: development of the study, discussion and article writing. WD: data analysis and discussion of the article. MT: data analysis and discussion of the article.

\section{CONFLICT OF INTEREST:}

The authors declare that there was no conflict of interest.

\section{AUTHOR'S DETAILS}

${ }^{2}$ Universidade Federal do Rio Grande do Sul (UFRGS), Porto Alegre (RS), Brasil

\section{REFERENCES}

1. Lluch E, Nijs J, De Kooning M, Van Dyck D, Vanderstraeten R, Struyf F, et al. Prevalence, incidence, localization, and pathophysiology of myofascial trigger points in patients with spinal pain: a systematic literature review. Journal of Manipulative \& Physiological Therapeutics. 2015;38(8):587600.

2. Kisner C, Colby LA. Exercícios terapêuticos: fundamentos e técnicas. Exercícios terapêuticos: Fundamentos e técnicas. 1992.

3. Simons D. Myofascial pain syndrome due to trigger points. International Rehabilitation Medicine Association. 1987.

4. Yeng LT, Kaziyama HHS, Teixeira MJ. Síndrome dolorosa miofascial. Revista de Medicina. 2001;80(spe1):94-110.

5. Barbosa I, Silva Pd, Silva KAF. Tratamento das disfunções da articulação temporomandibular por meio da técnica de dígito pressão. Revista Eletrônica Saúde CESUC. 2010;1.

6. Vasconcelos DA, Nascimento JDS, Dantas EHM, Alves JGB, Vitorino MS. Avaliação Eletromiográfica e Clínica da Técnica de Liberação Posicional em Pontos-Gatilho do Trapézio. Revista Inspirar Movimento \& Saude. 2012;4(4).

7. Bigongiari A, Franciulli PM, Souza FdA, Mochizuki L, Araujo RC. Análise da atividade eletromiográfica de superfície de pontos gatilhos miofasciais. Revista Brasileira de Reumatologia. 2008;48(6):319-24. 
8. Ge H-Y, Fernández-de-las-Peñas C, Yue S-W. Myofascial trigger points: spontaneous electrical activity and its consequences for pain induction and propagation. Chinese medicine. 2011;6(1):13.

9. Albertin A, Kerppers I, Amorim C, Costa R, Ferrari JC, Oliveira C. The effect of manual therapy on masseter muscle pain and spasm. Electromyography and clinical neurophysiology. 2010;50(2):107-12.

10. Motealleh A, Gheysari E, Shokri E, Sobhani S. The immediate effect of lumbopelvic manipulation on EMG of vasti and gluteus medius in athletes with patellofemoral pain syndrome: A randomized controlled trial. Manual therapy. 2016;22:16-21.

11. Konrad $P$. $A B C$ of EMG, A Practical Introduction to Kinesiological Electromyography version 1.4, Noraxon Inc. USA; 2006.

12. Hermens HJ, Freriks B, Disselhorst-Klug C, Rau G. Development of recommendations for SEMG sensors and sensor placement procedures. Journal of electromyography and Kinesiology. 2000;10(5):361-74.

13. La Torre M. Desenvolvimento de um software para processamento e análise de sinais biológicos utilizados em biomecânica. 2013.

14. Leotti VB, Coster R, Riboldi J. Normalidade de variáveis: métodos de verificação e comparação de alguns testes não-paramétricos por simulação. Revista HCPA Porto Alegre Vol 32, no 2 (2012), p 227-234. 2012.

15. Lindenau JD-R, Guimarães LSP. Calculando o tamanho de efeito no SPSS. Revista HCPA Porto Alegre Vol 32, n 3 (2012), p 363-381. 2012.

16. Fritz CO, Morris PE, Richler JJ. Effect size estimates: current use, calculations, and interpretation. Journal of experimental psychology: General. 2012;141(1):2.

17. Kim SA, Oh KY, Choi WH, Kim IK. Ischemic compression after trigger point injection affect the treatment of myofascial trigger points. Annals of rehabilitation medicine. 2013;37(4):541-6.
18. Nambi GS, Sharma R, Inbasekaran D, Vaghesiya A, Bhatt U. Difference in effect between ischemic compression and muscle energy technique on upper trepezius myofascial trigger points: Comparative study. International Journal of Health \& Allied Sciences. 2013;2(1):17.

19. Teixeira RF, Albuquerque RSd, Biana VdL, Teixeira GM. Efeito imediato da técnica de compressão isquêmica na inibição de pontos gatilhos. Fisioter Bras. 2011;12(5):324-9.

20. Montañez-Aguilera FJ, Valtueña-Gimeno N, Pecos-Martín D, ArnauMasanet R, Barrios-Pitarque C, Bosch-Morell F. Changes in a patient with neck pain after application of ischemic compression as a trigger point therapy. Journal of back and musculoskeletal rehabilitation. 2010;23(2):101-4.

21. Hains G, Descarreaux M, Hains F. Chronic shoulder pain of myofascial origin: a randomized clinical trial using ischemic compression therapy. Journal of Manipulative \& Physiological Therapeutics. 2010;33(5):362-9.

22. Kapandji A. Fisiologia articular: esquemas comentados de mecânica humana. São Paulo: Panamericana. Rio de Janeiro: Guanabara Koogan; 2000.

23. Montañez-Aguilera FJ, Martín DP, Masanet RA, Botella AC, Soler LB, Morell FB. Immediate effect of ultrasound and ischemic compression techniques for the treatment of trapezius latent myofascial trigger points in healthy subjects: a randomized controlled study. Journal of Manipulative \& Physiological Therapeutics. 2009;32(7):515-20.

24. Kostopoulos D, Nelson Jr AJ, Ingber RS, Larkin RW. Reduction of spontaneous electrical activity and pain perception of trigger points in the upper trapezius muscle through trigger point compression and passive stretching. Journal of Musculoskeletal Pain. 2008;16(4):266-78.

25. Forti F. Análise do sinal eletromiográfico em diferentes posicionamentos, tipos de eletrodos, ângulos articulares e intensidades de contração. Piracicaba: UNIMEP. 2005:34. 